\title{
Effect on Health-Related Outcomes of Interventions to Alter the Interaction Between Patients and Practitioners: A Systematic Review of Trials
}

Simon J. Griffin, $M S_{c}, D M^{1}$

Ann-Louise Kinmonth, MSc, $M D^{1}$

Marijcke W. M. Veltman, $P b D^{1}$

Susan Gillard, MSc ${ }^{1}$

Julie Grant, BSc ${ }^{2}$

Moira Stewart, $P b D^{2}$

${ }^{\prime}$ General Practice and Primary Care Research Unit, Department of Public Health and Primary Care, Institute of Public Health, Cambridge, UK

${ }^{2}$ Department of Family Medicine, University of Western Ontario, London, Ontario, Canada

\section{Conflict of interest: none reported}

\section{CORRESPONDING AUTHOR}

Simon J. Griffin, MSc, DM

General Practice and Primary Care

Research Unit

Department of Public Health

and Primary Care

Institute of Public Health

University Forvie Site

Robinson Way

Cambridge, CB2 2SR

sjg49@medschl.cam.ac.uk

\begin{abstract}
PURPOSE We wanted to identify published randomized trials of interventions to alter the interaction between patients and practitioners, develop taxonomies of the interventions and outcomes, and assess the evidence that such interventions improve patients' health and well-being.
\end{abstract}

METHODS Undertaking a systematic review of randomized trials, we sought trials in primary and secondary care with health-related outcomes, which we found by searching MEDLINE, HealthSTAR, and PsycINFO bibliographic databases through 1999. We also completed one round of manual citation searching.

RESULTS Thirty-five trials were included. Most were set in primary care in North America. Trials were heterogeneous in populations, settings, interventions, and measures. Interventions frequently combined several poorly described elements. Explicit theoretical underpinning was rare, and only one study linked intervention through process to outcome measures. Health outcomes were rarely measured objectively (6 of 35), and only 4 trials with health outcomes met predefined quality criteria.

Interventions frequently altered the process of interactions (significantly in $73 \%$, 22 of 30 trials). Principal outcomes favored the intervention group in $74 \%$ of trials (26 of 35), reaching statistical significance in $14(40 \%)$. Positive effects on health outcomes achieved statistical significance in $44 \%$ of trials (11 of 25); negative effects were uncommon (5 of $25,20 \%)$. Simple approaches to increasing the participation of patients in the clinical encounter, such as providing practitioners with a note from patients about their concerns beforehand, showed promise, as did more complex programs providing specific information about disease and attention to emotion. Apparently similar interventions varied in effectiveness across studies.

CONCLUSIONS Successful interactions between patients and their practitioners lie at the heart of medicine, yet there are few rigorous trials of well-specified interventions to inform best practice. Trial evidence suggests that a range of approaches can achieve changes in this interaction, and some show promise in improving patients' health. To advance knowledge further, we need to replicate promising studies using rigorous methods. These should include explicit theoretical frameworks designed to link effects on key communication and interaction characteristics through to effects on health outcomes.

Ann Fam Med 2004;2:595-608. DOI: 10.1370/afm.142.

\section{INTRODUCTION}

$\mathrm{t}$ is now generally accepted that effective communication is as essential to high-quality medical practice as is clinical knowledge. ${ }^{1-4} \mathrm{~A}$ body of evidence suggests that participation of the patient in all stages of the 
clinical encounter improves effectiveness and efficiency. Despite this evidence, practitioners often fail to listen or to elicit patients' concerns or to negotiate treatment options. ${ }^{5.7}$ This failure may be in part because skills are not effectively taught, ${ }^{1}$ but there may remain skepticism about the importance of partnership with patients in the consultation.

Much of the available evidence comes from observational studies in which a range of processes has been assessed. Identification and discussion of patient concerns, the provision of appropriate information, and patient involvement in choice of treatment options are associated with resolution of emotional and physical symptoms, greater treatment compliance, improved satisfaction, and fewer repeated consultations, referrals, and investigations. ${ }^{8}$ Interpretation of these studies can be affected by bias and confounding, however. In particular, apparent associations between patient participation in the clinical encounter and better health outcomes could occur if sicker patients participate less. ${ }^{9}$

Rigorous randomized trial evidence is required to establish causality, and a number of relevant trials have been conducted. Some have been included in reviews with nonrandomized designs ${ }^{8,10}$ or have focused on physician-training programs ${ }_{1}^{11}$ interventions directed at patients, ${ }^{12}$ or the context of the consultation. ${ }^{9}$ Although individual studies reporting significant effects on both emotional distress ${ }^{13}$ and disease control ${ }^{14}$ are quoted in teaching texts, ${ }^{1,2,15}$ no systematic reviews of their number, quality, or findings have yet been conducted.

We report the first comprehensive review of randomized controlled trials of interventions to alter the interaction between patients and practitioners in the consultation, including health outcomes. It aims to inform future research design and indicate promising approaches for further evaluation and application in practice.

\section{METHODS \\ Identification of Relevant Trials and Data Extraction}

We developed the search strategy using Delphi consensus methods (SJG, MWMV, ALK, MS) (Figure 1). Each term was combined with the Cochrane trials search strategy ${ }^{16}$ in MEDLINE (1966-1999), HealthSTAR (1975-1999) and PsycINFO (1967-1999) databases. We then hand-searched bibliographies of trials meeting the inclusion criteria. Titles and abstracts (where available) of identified reports were assessed. Full copies of reports resembling relevant trials were obtained. At least 2 authors independently checked them against inclusion criteria and extracted data onto standardized forms. Discrepancies were assessed by an independent researcher and resolved by discussion (SJG, MWMV, SG, JG, ALK, MS).

\section{Inclusion Criteria}

Studies set in primary or secondary medical or nursing care were included. Participants had to be allocated at random to an intervention aimed at altering the interaction between patients and practitioners within a consultation or office visit. The evaluation had to include assessment of a health outcome or satisfaction. Studies in any language were included.

Quality assessment took into account established criteria predicting the likely presence of bias. ${ }^{17}$ Criteria included allocation concealment at randomization and outcome assessment, losses to follow-up, and adjustment for cluster design, if present.

\section{Development of Taxonomies of Intervention Type and Measures}

Interventions used in trials to alter patient-practitioner interaction are varied and difficult to classify. We developed a taxonomy based on our theoretical understanding of the ways in which collaboration between patient and practitioner can be enhanced and may lead to improved outcomes. This framework has been described as the new clinical method. ${ }^{15}$ It involves the patient and practitioner reaching a mutual understanding of each others' explanatory models of illness and disease. It therefore takes into account the patient's

\section{Figure 1. Search terms.}

Patient-cent* red care

Patient compliance

Patient education

Patient participation

Patient satisfaction

Physician-patient relations

Professional-patient relations

Recall

Referral and consultation

Verbal behaviour

Patient acceptance of healthcare

Consumer participation

Consumer satisfaction

Doctor-patient communication

Doctor-patient relations

Nurse-patient communication

Nurse-patient relations

Hospital-patient relations

Interpersonal relations

Interviews

Medical history taking

Patient advocacy

Patient care team 
ideas, concerns, and expectations at all stages of the clinical interview, from gathering information through problem formulation to decisions about management. It is hypothesized that this method will lead to more precise framing of the problem and management that makes sense to the patient, which could enhance outcomes through several mechanisms. Specifically, a correct diagnosis will be matched to a more effective prescription. Involvement of the patient will lead to engagement in taking any agreed treatment. It will also mobilize a range of self-care activities tending to increase well-being and function through social, psychological, and perhaps even immunological mechanisms. ${ }^{18}$ Finally, the collaborative approach might reduce the mismatch between a patient's and the practitioner's representations of the problem and thereby increase efficiency through a reduction in unnecessary investigations, consultations, and unused medication. ${ }^{19}$

Approaches to changing the interaction between patient and practitioner within this framework can be aimed directly at patients (for example by a preconsultation leaflet or interview), via the practitioner (for example through courses), or at both parties. Components of interventions that we consider central to the new clinical method include those aimed at (1) increasing the patient's contribution at all stages of the clinical interview (patient activation), and (2) increasing the practitioner's ability to elicit and integrate the patient's views with the biomedical view (communication skills training).

More specifically, interventions can aim to (1) increase the patient's understanding of the biomedical model (provision of information about disease or treat-

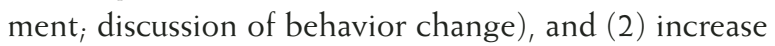
the practitioner's understanding of psychosocial aspects of the illness (attention to patient's emotion).

Having specified these components, we refined them by reading the studies and developed brief descriptions of each study intervention and comparison approach. Three authors undertook this process independently prior to consensus discussion (ALK, SJG, MS, SG). This effort added 2 further intervention subtypes: one where the practitioner receives information by a note or questionnaire before the clinical encounter to alert him or her to a patient's concerns or functional status (practitioner activation by patient questionnaire), and one where the practitioner changed the style of consultation between a biomedical or patient-centered approach (changes style). The extent to which these components were associated with improved health outcomes was then explored in the analyses.

A wide range of process measures was used. We defined measures of communication as subjective (selfreport) or objective (videotape, for example). Process measures most often assessed among patients included frequency of question asking, controlling behaviors, and overall involvement in the consultation, particularly the decision making. They also included patients' ratings of the extent to which the practitioner offered relevant, understandable information and explanation, and the extent to which patients felt understood and helped. Those processes measured among practitioners included the degree to which they elicited patient concerns, exhibited empathy, or considered psychosocial aspects of presenting complaints.

We classified health outcomes as objective measures of disease processes (for example, blood pressure and blood glucose concentrations), or subjective measures of illness experience by self-report (symptoms, anxiety, depression, functional status, well-being, and quality of life). We also included separately patient satisfaction with care and other health-related outcomes (health service costs, patient knowledge, and healthrelated behaviors including treatment adherence). The principal outcome for each study, when not specified by the author, was defined from sample size calculations, hypotheses, or aims.

\section{Analysis}

Descriptive analyses were undertaken of study settings, participants, quality, interventions, process, and outcome measures. Studies were too heterogeneous for meta-analysis. We grouped studies according to intervention type. Study process and outcome measures were reported as favoring intervention or comparison groups with accompanying probability (statistically significant at $P<.05$ ). We assessed the extent to which principal outcomes favored intervention or comparison groups across all studies. Then, for those with health outcomes, we assessed the effect of each prespecified category of intervention. The denominator for each comparison was the number of studies reporting the relevant outcome.

\section{RESULTS}

\section{Search Strategy}

More than 21,200 reports were identified, of which 148 were potentially relevant and fully assessed. Thirty-five trials met the inclusion criteria. The most common reasons for exclusion were nonrandomized design, no reported health outcomes, and the intervention not specifically targeting patient-practitioner interactions. Most were reported after 1995. Two similar but distinct trials were reported in one article. ${ }^{20}$ Data were incomplete for one trial despite correspondence with the author. ${ }^{21}$ Characteristics of included trials are summarized in Table 1. 


\section{Table 1. Characteristics of Included Trials}

\begin{tabular}{|c|c|c|c|c|c|}
\hline $\begin{array}{l}\text { Author, } \\
\text { Year }\end{array}$ & $\begin{array}{l}\text { Setting, } \\
\text { Country }\end{array}$ & Patient Group & $\begin{array}{l}\text { Health } \\
\text { Outcome }\end{array}$ & $\begin{array}{c}\text { Patients } \\
\text { Entered } \\
\text { No. }\end{array}$ & $\begin{array}{l}\text { Treatment } \\
\text { Allocation* }\end{array}$ \\
\hline \multicolumn{6}{|c|}{ Interventions delivered directly to patients } \\
\hline Greenfield et al, $1985^{22}$ & Hospital OPD, USA & Chronic disease (peptic ulcer) & Subjective & 45 & Inadequate \\
\hline Greenfield et al, $1988^{14}$ & Hospital OPD, USA & Chronic disease (diabetes) & Objective & 73 & Inadequate \\
\hline Kaplan et al, $1989^{21}$ & Hospital OPD, USA & Chronic disease (hypertension) & Objective & 105 & Inadequate \\
\hline Thompson et al, 1990a & Primary care, USA & Other disease (gynecology) & Subjective & 66 & Adequate \\
\hline Thompson et al, $1990 b^{20}$ & Primary care, USA & Other disease (gynecology) & Subjective & 105 & Adequate \\
\hline Butow et al, $1994^{23}$ & Hospital OPD, Aus & Other disease (cancer) & Subjective & 142 & Inadequate \\
\hline Street et al, $1995^{24}$ & Hospital OPD, USA & Other disease (breast cancer) & Subjective & 60 & Inadequate \\
\hline McCann \& Weinman, $1996^{25}$ & Primary care, UK & GP non specific disease & Satisfaction & 120 & Adequate \\
\hline Davison \& Degner, $1997^{26}$ & Hospital OPD, Canada & Other disease (prostate cancer) & Subjective & 60 & Adequate \\
\hline Kravitz et al, $1997^{27}$ & Primary care, USA & Other disease (not specified) & Satisfaction & 396 & Inadequate \\
\hline Fleissig et al, $1999^{28}$ & Hospital OPD, UK & Other disease (not specified) & Satisfaction & 1,683 & Inadequate \\
\hline \multicolumn{6}{|c|}{ Interventions delivered via practitioners } \\
\hline Thomas, $1978^{29}$ & Primary care, UK & GP nonspecific disease & Subjective & 200 & Inadequate \\
\hline Schulman \& Swain, $1980^{30}$ & Hospital OPD, USA & Chronic disease (hypertension) & Satisfaction & 105 & Inadequate \\
\hline Evans et al, $1987^{31}$ & Primary care, Aus & GP nonspecific disease & Subjective & $400^{\ddagger}$ & Inadequate \\
\hline Thomas, $1987^{32}$ & Primary care, UK & GP nonspecific disease & Subjective & 200 & Inadequate \\
\hline Olsson et al, $1989^{33}$ & Primary care, Sweden & GP nonspecific disease & Subjective & 100 & Adequate \\
\hline Savage, $1990^{39}$ & Primary care, UK & GP nonspecific disease & Subjective & 350 & Inadequate \\
\hline Evans et al, $1992^{35}$ & Hospital OPD, Aus & Other disease (not specified) & Satisfaction & Missing & Inadequate \\
\hline Roter et al, $1995^{13}$ & Primary care, USA & GP non specific disease & Subjective & 648 & Inadequate \\
\hline Smith et al, $1995^{36}$ & Primary care, USA & Other disease (not specified) & Satisfaction & 181 & Adequate \\
\hline Meland et al, 199737,38 & Primary care, Norway & Risk of disease (CHD) & Objective & 127 & Inadequate \\
\hline Kinmonth et al, $1998^{39}$ & Primary care, UK & Chronic disease (diabetes) & Objective & 360 & Adequate \\
\hline Pill et al, $1998^{40}$ & Primary care, UK & Chronic disease (diabetes) & Objective & 190 & Adequate \\
\hline Smith et al, $1998^{41}$ & Primary care, USA & GP nonspecific disease & Subjective & Missing & Inadequate \\
\hline Peters et al, $1999^{42}$ & Primary care, UK & $\begin{array}{l}\text { Other disease (cervical } \\
\text { dysplasia) }\end{array}$ & Subjective & 270 & Adequate \\
\hline Thom et al, $1999^{43}$ & Primary care, USA & GP nonspecific disease & $\begin{array}{l}\text { Other health } \\
\text { related }\end{array}$ & 414 & Inadequate \\
\hline Brown Betz et al, $1999^{44}$ & Primary care, USA & GP nonspecific disease & Satisfaction & $4,941^{\ddagger}$ & Adequate \\
\hline \multicolumn{6}{|c|}{ Interventions delivered both to the patient and to the practitioner } \\
\hline Lewis et al, $1991^{45}$ & Primary care, USA & GP nonspecific disease & Subjective & 141 & Inadequate \\
\hline Katon et al, $1995^{46}$ & Primary care, USA & Chronic disease (depression) & Subjective & 217 & Inadequate \\
\hline Rubenstein et al, $1995^{47}$ & Primary care, USA & GP nonspecific disease & Subjective & 557 & Adequate \\
\hline Joos et al, $1996^{48}$ & Hospital OPD, USA & Chronic disease (not specified) & $\begin{array}{l}\text { Other health } \\
\text { related }\end{array}$ & 409 & Inadequate \\
\hline Hornberger et al, $1997^{49}$ & Primary care, USA & GP nonspecific disease & Subjective & 201 & Inadequate \\
\hline Wagner et al, $1997^{50}$ & Hospital OPD, USA & Chronic disease (epilepsy) & Satisfaction & 163 & Adequate \\
\hline Maly et al, $1999^{51}$ & Primary care, USA & (hronic disease not specified) & Subjective & 265 & Adequate \\
\hline Reuben et al, $1999^{52}$ & Community, USA & Other disease (multiple types) & Objective & 363 & Adequate \\
\hline
\end{tabular}

USA = United States of America; OPD = outpatient department; Aus = Australia; UK = United Kingdom; GP = patient attending in general/family practice;

$\mathrm{CHD}=$ coronary heart disease.

* Allocation concealment at treatment allocation was adequate if a clear method (for example central randomization, sealed envelopes or random numbers) was reported.

† Allocation concealment at outcome assessment was adequate if it was reported that assessors were unaware of participants' study group allocation.

₹ Numbers of patients analyzed in the trial.

\section{Participants and Settings}

Most trials were undertaken in primary care in North America. All were reported in English. More than 13,500 patients (median 200, interquartile range, 105-380) participated. Most trials involved patients who had a chronic problem $(\mathrm{n}=15$ trials), including cardiovascular disease, diabetes, epilepsy, depression, or cancer of breast or prostate, or they enrolled a sample of patients consulting in primary care $(\mathrm{n}=11)$. 


\begin{tabular}{|c|c|c|}
\hline $\begin{array}{c}\text { Outcome } \\
\text { Assessment }\end{array}$ & Duration & $\begin{array}{l}\text { Percent } \\
\text { Lost to } \\
\text { Follow-up }\end{array}$ \\
\hline Adequate & 8 weeks & $<30$ \\
\hline Adequate & 12 weeks & $<30$ \\
\hline Inadequate & 12 weeks & Missing \\
\hline Inadequate & Immediate & $>30$ \\
\hline Inadequate & Immediate & $>30$ \\
\hline Inadequate & 3 weeks & $>30$ \\
\hline Inadequate & 1 week & $<30$ \\
\hline Adequate & Immediate & $<30$ \\
\hline Inadequate & 6 weeks & $<30$ \\
\hline Inadequate & Immediate & $<30$ \\
\hline Adequate & Immediate & $>30$ \\
\hline Inadequate & 1 month & $<30$ \\
\hline Inadequate & Immediate & $<30$ \\
\hline Inadequate & 4 weeks & Missing \\
\hline Inadequate & 2 weeks & $<30$ \\
\hline Adequate & 2 days & $<30$ \\
\hline Inadequate & 1 week & $>30$ \\
\hline Adequate & Immediate & Missing \\
\hline Adequate & 6 months & $<30$ \\
\hline Inadequate & Immediate & Missing \\
\hline Inadequate & 1 year & $<30$ \\
\hline Adequate & 1 year & $>30$ \\
\hline Adequate & 18 months & $<30$ \\
\hline Adequate & 4 weeks & Missing \\
\hline Adequate & 4 months & $<30$ \\
\hline Inadequate & 6 months & $<30$ \\
\hline Adequate & 3 months & $<30$ \\
\hline Adequate & Immediate & \\
\hline Adequate & 7 months & \\
\hline Adequate & 6 months & \\
\hline Inadequate & 12 months & $<30$ \\
\hline Inadequate & Immediate & $<30$ \\
\hline Inadequate & Immediate & $<30$ \\
\hline Adequate & 2 weeks & $<30$ \\
\hline Adequate & 15 months & $<30$ \\
\hline
\end{tabular}

\section{Trial Quality}

Trial quality varied. Descriptions of allocation concealment at randomization and outcome assessment were frequently inadequate or missing (21 and 18 trials, respectively). Follow-up was short (median 4 weeks, interquartile range 0-26). Losses to follow-up were either not reported or exceeded $30 \%$ in more than a quarter of studies. Clustering was present in 15 of the included trials ${ }^{13,31,35-37,39-45,47-49}$; in 10 some adjustment was made for this clustering in the analysis. ${ }^{13,36,39,41-}$ 45,48,49 Health-related principal outcomes were measured objectively in 6 studies and subjectively in 19 studies. Four measured symptom resolution, ${ }^{29,32-34}$ 10 measured anxiety or depression, ${ }^{*}$ and 5 measured well-being or functional status. ${ }^{22-24,47,51}$ Two studies measured adherence to treatment. ${ }^{43,48}$ In 8 studies satisfaction was the principal outcome. Only 4 studies with health outcomes met our prespecified quality criteria. ${ }^{33,42,51,52}$

Characteristics of interventions are summarized in Table 2. Eleven interventions were aimed at the patient directly, 16 were administered by the practitioner, and 8 used a combination of these approaches. Most interventions $(n=23)$ involved activation of the patient in the consultation, which included stimulating patients to take a more active role, for example, by considering questions to ask in advance of the consultation $(\mathrm{n}=18){ }^{\dagger}$ or writing down needs and expectations to be given to practitioners, thus activating them in turn $(\mathrm{n}=5) .{ }^{47-51}$ Eleven studies evaluated training practitioners in communication skills. ${ }^{\ddagger}$ Skills included listening, eliciting patients' views, and negotiating treatment plans. ${ }^{30}$

In 12 studies $^{\S}$ information about disease or treatment and in 7 discussion of behavior change $30,36,37,39,40,41,46$ was a main feature of the intervention. In 14 studies there was explicit attention to emotion (for example reference to affect, trust or patients' concerns)," always in the context of more complex interventions. Classification of attention to emotional issues was the hardest on which to agree. In 4 studies practitioners simply altered their consultation style. ${ }^{29,32-34}$

Interventions most commonly incorporated booklets, letters, or tapes either alone or in combination with training sessions, and they varied widely in intensity and complexity. Comparison groups were split fairly evenly between usual care $(\mathrm{n}=18)^{\mathfrak{f}}$ and attention control $(\mathrm{n}=17)$. $^{*}$

\section{Effects on the Process of the Consultation}

Effects of the intervention on the process of the consultation were measured in most trials (30 of $35,86 \%$ ),

\footnotetext{
* References 13, 20, 26, 31, 41, 42, 45, 46, 49.

† References 14, 20-28, 39, 40, 42, 43, 45, 46, 52.

† References 13, 31, 35, 36, 39, 40, 41, 43-45, 48.

$\S$ References 13, 14, 21, 22, 24, 26, 30, 33, 42, 46, 51, 52.

|| References 13, 14, 21, 22, 24, 39-41, 43-45, 48-50.

If References 14, 20-26, 29, 32-34, 37, 39, 42, 45, 51.

\# References $13,27,28,30,31,35,36,40,41,43,44,46-50,52$
} 


\section{Table 2. Characteristics of the Interventions in Included Trials}

Author, Year Intervention Group

Comparison Group

\section{Interventions delivered directly to patients}

Greenfield et al, $1985^{22}$

Preconsultation interview, skills training and materials

Patient activation with attention to emotion and provision of information about treatment decisions

Greenfield et al, $1988^{14}$

Preconsultation interview, skills training and materials

Patient activation with attention to emotion and provision of information about treatment decisions

Kaplan et al, $1989^{21}$

Thompson et al, $1990 a^{20}$

Thompson et al, $1990 b^{20}$

Butow et al, $1994^{23}$

Street et al, $1995^{24}$

McCann \& Weinman, $1996^{25}$

Davison \& Degner, $1997^{26}$

Kravitz et al, $1997^{27}$

Fleissig et al, $1999^{28}$

Preconsultation interview, skills training and materials

Patient activation with attention to emotion and provision of information about treatment decisions

Preconsultation, list of possible health concerns, and leaflet encouraging question asking

Patient activation

Preconsultation, message from physician encouraging question asking, or checklist of information to be obtained during consultation

Patient activation

Preconsultation, leaflet encouraging question asking

Patient activation

Multimedia program providing information about disease and treatment and encouragement to ask questions, explain concerns, and offer opinion in consultation

Patient activation with provision of information about disease and treatment and attention to emotion

Preconsultation, leaflet encouraging questions, and ideas about causes, diagnosis, and treatment

Patient activation

Preclinic interview facilitating provision of information, encouraging questions and participation in decisions

Patient activation and provision of information about disease

Preconsultation, patient completes request for services and is interviewed on expectations for care in consultation

Patient activation

Preconsultation help card, and encouragement to ask questions

Patient activation

\section{Interventions delivered via practitioners}

Thomas, $1978^{29}$

Schulman E Swain, $1980^{30}$

During consultation, provision of positive information about diagnosis and treatment

Changes style of information giving

During consultation, practitioner provided information about hypertension and its management alone, or with contingency contracting

Provision of information about disase and discussion of behavior change

Evans et al, $1987^{31}$

Lecture, booklet, discussion

Communication skills training

Thomas, $1987^{32}$

Olsson et al, $1989^{33}$

Savage, $1990^{39}$

Evans et al, $1992^{35}$

Roter et al, $1995^{13}$
During consultation, certainty about diagnosis, treatment and prognosis

Changes style of information giving

During consultation, positive style, personal, with provision of information about disease (prognosis)

Changes style of information giving and provides information about disease

During consultation, shared style, eliciting patients ideas about symptoms, diagnosis, and treatment

Changes style of information giving

Lectures small groups and videotape feedback

Communication skills training

Course with simulated psychiatric patients and videos

Communication skills training with attention to emotion and information about disease management
Preconsultation interview about disease course, treatment, self-care, and adherence to treatment

Preconsultation interview about disease course and treatment

Preconsultation interview about disease course, treatment, and self-care

Usual care and questionnaire on waiting room facilities

Usual care and questionnaire on waiting room facilities

Handout on cancer services available

Given same material in brochure form without treatment options.

Leaflet giving dietary advice

Social interview and unfacilitated information pack

Usual care

Usual care

Given positive information that there was no illness

Usual care

Usual care

Uncertainty about diagnosis

Less positive diagnosis, less personal, no information on prognosis

Directive style, giving clear information on diagnosis, treatment and prognosis

Usual clerking

Usual practice 
Table 2. continued

\section{Author, Year}

Smith et al, $1995^{36}$

Meland et al, 199737,38

Kinmonth et al, $1998^{39}$

Pill et al, $1998^{40}$

Smith et al, $1998^{41}$

Peters et al, $1999^{42}$

Thom et al, $1999^{43}$

Brown Betz et al, $1999^{44}$

\section{Interventions deliv
Lewis et al, $1991^{45}$}

Katon et al, $1995^{46}$

Rubenstein et al, $1995^{47}$

Joos et al, $1996^{48}$

Hornberger et al, $1997^{49}$

Wagner et al, $1997^{50}$

Maly et al, $1999^{51}$

Reuben et al, $1999^{52}$

\section{Intervention Group}

Communication skills training with discussion of behavior change and skills in disease management

Training using video and cognitive self-help materials for patients Discussion of behavior change

Communication skills training in listening, eliciting patient's agenda, and supporting behavior change

Communication skills training, patient activation with attention to emotion, and discussion of behavior change

Practice based training in eliciting patient concerns and discussing behavior change

Communication skills training, patient activation with attention to emotion, and discussion of behavior change

Course of seminars, video and booklets on communication, and disease management skills

Communication skills training with attention to emotion, discussion of behavior change

Information leaflets and invitation to consult practice nurse who was trained to present information on disease, risk, and treatment and encourage women to ask questions

Patient activation and information about disease management

Workshop

Communication skills training with patient activation and attention to emotion

Workshops

Communication skills training program with attention to emotion

the patient and to the practitioner

Separate communication skills training sessions, videos and materials for patients and practitioners

Child patient and parent activation and practitioner communication skills teaching, with attention to emotion

Videos and materials on cognitive-behavioral management of depression and encouraging question asking. Practitioner course on treatment of depression and case-based feedback

Patient activation, information about disease management and discussion of behavior change

Patients completed functional status questionnaire preconsultation, practitioners taught questionnaire interpretation

Patient activation, practitioner activated by patient questionnaire

Preconsultation, patient completes request for service form, practitioners taught communication skills

Patient activation, practitioner activated by patient questionnaire with attention to emotion, and communication skills training

Preconsultation, patient completes request for services form including emotional needs

Patient activation, practitioner activated by patient questionnaire, with attention to emotion

Preconsultation; patients completed functional status questionnaire in consultation, practitioners taught interpretation

Patient activation, practitioner activated by patient questionnaire, with attention to emotion

Preconsultation; patient recorded two questions which were attached to the medical record, given medical notes and glossary

Patient activation, information about disease, and practitioner activated by patient note

Specialist advice to practitioners via telephone; provision of information about disease and its treatment. Preconsultation booklet and telephone call to patient

Patient activation and information about disease management

\section{Comparison Group}

Usual care

Usual care and leaflets

Usual care and provision of information on disease

Usual care

Usual care

Disease information leaflet

Usual care

Usual practice

Course on bicycle safety (patient) assessment of febrile child (practitioner)

Usual care

Usual care

Usual care

Usual care

Usual care

Information sheet and patient suggestion list

Usual care and nonstudy incentives 


\begin{tabular}{|c|c|c|c|c|}
\hline $\begin{array}{l}\text { Author, } \\
\text { Year }\end{array}$ & $\begin{array}{l}\text { Objective Health } \\
\text { Outcomes (Disease } \\
\text { Processes)* }\end{array}$ & $\begin{array}{l}\text { Subjective Health } \\
\text { Outcomes (Illness } \\
\text { Experience) }\end{array}$ & $\begin{array}{l}\text { Other } \\
\text { Outcomes }\end{array}$ & Satisfaction \\
\hline \multicolumn{5}{|c|}{ Interventions delivered directly to patients } \\
\hline Greenfield et al, $1985^{22}$ & & $\begin{array}{l}\text { Pain: }+ \\
\text { Functional status: }++\end{array}$ & $\begin{array}{l}\text { Knowledge: - - } \\
\text { Cost: }+\end{array}$ & - \\
\hline Greenfield et al, $1988^{14}$ & $\mathrm{HbA}_{1 \mathrm{c}}:++$ & $\begin{array}{l}\text { Quality of life: }++ \\
\text { Functional status: }++\end{array}$ & $\begin{array}{l}\text { Knowledge: }+ \\
\text { Cost: }++\end{array}$ & - \\
\hline Kaplan et al, $1989^{21}$ & Blood pressure: ++ & $\begin{array}{l}\text { Functional status: }++ \\
\text { Well-being: missing }\end{array}$ & Cost: missing & Missing \\
\hline Thompson et al, $1990 a^{20}$ & & Anxiety: + + & Cost: + & $0_{\infty}$ \\
\hline Thompson et al, $1990 b^{20}$ & & Anxiety: + & $\begin{array}{l}\text { Knowledge: } \\
\text { checklist - } \\
\text { Message + }\end{array}$ & ++ \\
\hline Butow et al, $1994^{23}$ & & Quality of life: $0 \infty$ & Knowledge: - & - \\
\hline Street et al, $1995^{24}$ & & Well-being: $0^{+}$ & Knowledge: + & \\
\hline McCann \& Weinman, $1996^{25}$ & & & Cost: - - & + \\
\hline Davison \& Degner, $1997^{26}$ & & $\begin{array}{l}\text { Anxiety: + } \\
\text { Depression: + }\end{array}$ & & \\
\hline Kravitz et al, $1997^{27}$ & & & & $0^{\dagger}$ \\
\hline Fleissig et al, $1999^{28}$ & & & & ++ \\
\hline \multicolumn{5}{|c|}{ Interventions delivered via practitioners } \\
\hline Thomas, $1978^{29}$ & & Symptom resolution: - & & \\
\hline Schulman E Swain, $1980^{30}$ & & & & + \\
\hline Evans et al, $1987^{31}$ & & Anxiety: + + & & ++ \\
\hline Thomas, $1987^{32}$ & & Symptom resolution: ++ & & \\
\hline Olsson et al, $1989^{33}$ & & Symptom resolution: ++ & Cost: not analyzed & ++ \\
\hline Savage, $1990^{39}$ & & Symptom resolution: - & Cost: - & -- \\
\hline Evans et al, $1992^{35}$ & & & Cost: $0^{+}$ & ++ \\
\hline Roter et al, $1995^{13}$ & & Depression: ++ & Cost: - & \\
\hline Smith et al, $1995^{36}$ & & & & ++ \\
\hline Meland et al, $1997^{37,38}$ & $\begin{array}{l}\text { Blood presure: + } \\
\text { Cholesterol: }+ \\
\text { Thiocyanate: + }\end{array}$ & $\begin{array}{l}\text { Quality of life: + } \\
\text { Well-being: + } \\
\text { Functional status: + }\end{array}$ & $\begin{array}{l}\text { Health behavior: } \\
\text { exercise }+ \\
\text { Smoking } 0^{+} \\
\text {Cost: }+\end{array}$ & -- \\
\hline Kinmonth et al, $1998^{39}$ & $\begin{array}{l}\mathbf{H b A}_{1 \mathrm{c}} \mathbf{\text { + }}+ \\
\text { Cholesterol: - } \\
\text { Triglyceride - - } \\
\text { Body mass index: - - } \\
\text { Blood pressure: - } \\
\text { Albumin/creatine: - }\end{array}$ & $\begin{array}{l}\text { Quality of life: + } \\
\text { Well-being: + + }\end{array}$ & $\begin{array}{l}\text { Health behavior: } \\
\text { diet } 0^{+} \\
\text {Exercise/smoking - } \\
\text { Knowledge: - - }\end{array}$ & ++ \\
\hline Pill et al, $1998^{40}$ & $\begin{array}{l}\mathbf{H b A}_{1 \mathbf{c}}:- \\
\text { Blood pressure: - } \\
\text { Body mass index: - }\end{array}$ & $\begin{array}{l}\text { Diabetic complication: + } \\
\text { Functional status: - - } \\
\text { Well-being: } 0^{+}\end{array}$ & $\begin{array}{l}\text { Health behavior: } 0^{\dagger} \\
\text { Cost: } 0^{+}\end{array}$ & -- \\
\hline Smith et al, $1998^{41}$ & & $\begin{array}{l}\text { Depression: + } \\
\text { Functional status: + }\end{array}$ & Knowledge: missing & + \\
\hline Peters et al, $1999^{42}$ & & $\begin{array}{l}\text { Perceptions of health: - } \\
\text { Anxiety: + } \\
\text { Functional status: + }\end{array}$ & $\begin{array}{l}\text { Health behavior: + } \\
\text { Cost: - - }\end{array}$ & \\
\hline Thom et al, $1999^{43}$ & & & $\begin{array}{l}\text { Health behavior: } 0^{+} \\
\text {Cost: } 0^{+}\end{array}$ & + \\
\hline Brown Betz et al, $1999^{44}$ & & & & - \\
\hline
\end{tabular}


Table 3. continued

\begin{tabular}{|c|c|c|c|c|}
\hline $\begin{array}{l}\text { Author, } \\
\text { Year }\end{array}$ & $\begin{array}{l}\text { Objective Health } \\
\text { Outcomes (Disease } \\
\text { Processes)* }\end{array}$ & $\begin{array}{l}\text { Subjective Health } \\
\text { Outcomes (Illness } \\
\text { Experience) }\end{array}$ & $\begin{array}{l}\text { Other } \\
\text { Outcomes }\end{array}$ & Satisfaction \\
\hline \multicolumn{5}{|c|}{ Interventions delivered both to the patient and to the practitioner } \\
\hline Lewis et al, $1991^{45}$ & & Anxiety: + & Knowledge: ++ & ++ \\
\hline Katon et al, $1995^{46}$ & & $\begin{array}{l}\text { Depression: }+ \\
\text { Functional status: missing }\end{array}$ & Health behavior: ++ & ++ \\
\hline Rubenstein et al, $1995^{47}$ & & Functional status: ++ & & \\
\hline Joos et al, $1996^{48}$ & & & $\begin{array}{l}\text { Health behavior: } \\
\text { medication - } \\
\text { Appointments: } 0_{\infty}\end{array}$ & + \\
\hline Hornberger et al, $1997^{49}$ & & $\begin{array}{l}\text { Depression: }+ \\
\text { Anxiety: }++ \\
\text { Functional status: } 0^{+}\end{array}$ & Cost: - - & + \\
\hline Wagner et al, $1997^{50}$ & & & Cost: - & + \\
\hline Maly et al, $1999^{51}$ & & Functional status: ++ & $\begin{array}{l}\text { Health behavior: }+ \\
\text { Cost: }+\end{array}$ & \\
\hline Reuben et al, $1999^{52}$ & Mortality: + & Functional status: ++ & & + \\
\hline \multicolumn{5}{|c|}{$\begin{array}{l}\mathrm{HbA}_{1 \mathrm{C}}=\text { glycosylated hemoglobin; }++=\text { result significantly favors intervention group; }+=\text { result favors intervention group; }--=\text { result significantly favors control } \\
\text { group; }-=\text { result favors control group; } 0 \infty=\text { outcome identical in both groups; cost }=\text { health services cost. }\end{array}$} \\
\hline \multicolumn{5}{|c|}{ Note: Principal outcome for each study in boldface; not analyzed = results not reported in original paper; missing = no data presented in the paper. } \\
\hline
\end{tabular}

usually by patient $(n=21)$ or practitioner self-report $(\mathrm{n}=11)$. Objective measures were used in 15 studies (patient, 10; practitioner, 12). ** Processes significantly favored the intervention groups in most studies (22 of $30,73 \%)$. In 6 studies at least 1 process deteriorated $^{20,34,44,45,49,52}$ (2 significantly ${ }^{34,49}$ ), although in 4 of these studies other process measures significantly favored the intervention. ${ }^{20,44,45,49}$ (The effects of the interventions on the effects of consultations are dis-

played as supplemental data in Table $2 a$, which is available online only at: http://www.annfammed. org/cgi/content/full/2/6/595/DC1).

\section{Effects on Patient Outcomes}

Table 3 summarizes the effects of the interventions on outcomes and the direction of results in relation to the main intervention categories.

\section{Overall Pattern of Results Across All Studies}

In 18 of 35 studies at least 1 health-related outcome significantly favored the intervention group. Multiple measures of outcome were used, however, and in 8 studies at least 1 outcome significantly favored the control group. Objective measures of health favored the intervention in 5 of $6(83 \%)$ studies and the comparison group in 2 of these studies. Subjective measures of

** References $13,14,21-25,34,35,40,41,45,47-49$ health favored the intervention in 21 of 25 (84\%) and the comparison group in 4 of 25 (16\%).

Health-related behaviors favored the intervention group in 4 of $8(50 \%)$ studies and the control group in 2 of $8(25 \%)$. Knowledge favored the intervention group in 4 of $8(50 \%)$ and the control group in 4 of 8 $(50 \%)$. Duration of consultations was shorter in 4 of 12 (33\%) intervention groups ${ }^{14,20,22,51}$ and 6 of $12(50 \%)$ controls. ${ }^{13,25,34,42,49,50}$ Other costs were rarely measured. ${ }^{13,14,37,40,43}$ Satisfaction with care was higher in the intervention group in 17 of $27(63 \%)$ studies and in the comparison group in 7 of 27 (26\%).

Interventions were evaluated with multiple measures of process and outcome, but interrelationships were rarely hypothesized or tested. In only 1 study was there any trial analysis of the effect of the intervention through process on outcome. ${ }^{22}$ Other studies analyzed the effects of the intervention on process and outcome separately.

\section{Principal Outcomes Across All Studies}

Principal outcomes favored the intervention groups in 26 of $35(74 \%)$ trials, significantly in 14 . Among 25 studies with a principal health outcome, 20 favored the intervention group (80\%), 11 significantly (44\%). Among 6 studies measuring disease processes objectively, only 2 reported statistically significant benefits (33\%). Neither of 2 studies with behavior change 
(medication adherence) as the principal outcome favored the intervention group. ${ }^{43,48}$ Among 8 studies with satisfaction as the principal outcome, 6 favored the intervention group (75\%), 3 significantly (37\%).

\section{Effect of Different Categories of Intervention on Health Outcomes}

Interventions delivered directly to patients showed a positive effect on any health outcome in 6 of $8(75 \%)$ studies, reaching significance in $4(50 \%)$ and no negative effects. Interventions delivered via practitioners showed a positive effect in 9 of 11 (82\%) studies, reaching significance in $5(45 \%)$ and negative effects in 5 of $11(45 \%)$, reaching significance in 2 . Interventions targeting both practitioners and patients showed a positive effect in 6 of 7 (86\%) studies where measured, significantly so in $4(57 \%)$ and no negative effects.

Patient activation was associated with improved health outcomes in 15 of 17 trials in which they were measured, significantly so in 9. Three studies reported health outcomes favoring the control group, significantly in 2 . Both simple approaches, such as preconsultation requests for services, ${ }^{49}$ and more complex interventions, including preconsultation interviews, skills training, and materials for patients, significantly improved health outcomes. ${ }^{14,21}$ Not all studies favored the intervention group, and some interventions had negative effects. ${ }^{23,24,39,40}$ Two complex interventions involving patient activation, evaluated in the United States ${ }^{14,21}$ reported particularly large benefits, not achieved in pragmatic trials among the same patient group in this country. ${ }^{39,40}$

Isolation of potentially active ingredients of patient activation was not easy. For example, in the study of a complex intervention cited above, patients with diabetes were coached in question asking and negotiating skills and provided with information from the medical records before they saw their practitioner. ${ }^{14}$ A clinically important effect of the intervention ( $2 \%$ difference in $\mathrm{HbA}_{1 \mathrm{c}}$ ) was found at 12 weeks; however, 4 other interventions including encouragement to ask questions failed to show significantly improved health outcomes. Butow and Dunn ${ }^{23}$ randomly assigned patients attending their first oncology outpatient appointment to receive a prompt for question asking or an information leaflet, with no effect on subsequent psychological adjustment or satisfaction. Street et $\mathrm{al}^{24}$ randomized women with breast cancer to an interactive multimedia program encouraging question asking or to an information brochure before consultations, with no effect on optimism. Kinmonth et $\mathrm{al}^{39}$ randomly assigned practitioner groups to communication skills training. Skills included listening to and eliciting the agenda of patients with newly diagnosed diabetes. Patients were also encouraged by leaflet to ask questions. The study showed a significant increase in well-being among the intervention group, but also significant increases in body mass index $\left(2 \mathrm{~kg} / \mathrm{m}^{2}\right)$ and triglycerides $(0.4$ $\mathrm{mmol} / \mathrm{L})$. In a somewhat similar study, Pill et $\mathrm{al}^{40}$ found were no significant effects on $\mathrm{HbA}_{1 \mathrm{c}}$, and functional status was lower in the intervention group.

All 3 studies in which practitioners were activated by a note or questionnaire completed by patients showed significant improvements in functional status or anxiety. ${ }^{47,49,51}$ All 6 studies of communication skills training for practitioners reported health outcomes favoring the intervention group, 3 achieving statistical significance. ${ }^{13,31,39}$ Two studies reported significantly better health outcomes in the comparison group..$^{39,40}$

Provision of information about disease and its treatment was combined with a range of other approaches in 11 studies, 7 of which significantly favored the intervention, ${ }^{13,14,21,22,33,51,52}$ with a nonsignificant negative outcome in only one. ${ }^{42}$ One of 5 interventions including discussion of behavioral change was associated with a significantly positive health outcome ${ }^{39}$ and 2 with significant negative outcomes. ${ }^{39,40}$

Seven of 11 interventions with attention to emotion were associated with significantly positive health outcomes, ${ }^{13,14,21,22,39,49}$ and 2 with (significant) negative outcomes. ${ }^{39,40}$ Two of 4 interventions where practitioners altered their consultation style were associated with significantly positive outcomes, ${ }^{32,33}$ (which is displayed online only as supplemental data in Table 4, at: http://www.annfammed.org/cgi/content/full/ 2/6/595/DC1).

\section{Effect on Health Outcomes in High-Quality Studies}

Only 4 studies met all predefined quality crite-

ria. ${ }^{42,33,51,52}$ Interventions ranged from a complex multidisciplinary intervention to improve geriatric care to a change to a more personal, positive style of consultation by the family doctor, and from encouragement of women to ask questions at cervical screening with the office nurse to preconsultation recording by patients of their 2 main questions for the practitioner (Table 2). In 3 of the studies subjective health outcomes were significantly better in the intervention group (Table 3 ).

\section{DISCUSSION}

\section{Trial Quality}

This review of trials of interventions to alter the interaction between patient and practitioner and their effects on health-related outcomes is the most comprehensive yet undertaken. It shows clear weaknesses in the field. Only 35 trials up to the end of 1999 were identified by clear criteria. Studies tended to be small 
and short, with major design limitations. Only 4 studies with health outcomes met our prespecified quality criteria, which were selected for their ability to predict the likely presence of bias. ${ }^{17}$ It could be argued that these criteria could be wider still; for example, populations were often poorly characterized, and measures of process and outcome were unvalidated. Other reviews have analyzed these shortcomings in detail. ${ }^{12}$ Here we focus on the limitations in description and evaluation of the interventions, which were often multifaceted, poorly described, and not clearly linked to measures of their likely effects. The mechanisms by which components of the intervention were hypothesized to affect processes within the consultation to influence outcomes (the underlying causal models) were rarely made explicit, and only once tested. ${ }^{53}$ Such testing is essential for the field to advance. For example, this review showed the difficulty of isolating the effects of interventions to promote question asking. Kidd et al ${ }^{54}$ have recently drawn on a theoretical framework from psychology to overcome cognitive and affective barriers to question asking. Brief interventions to promote question asking are based on the studies by Roter, ${ }^{55}$ Greenfield et al, ${ }^{22}$ and Thompson. ${ }^{20}$ In a randomized design, interventions were offered to patients attending a hospital diabetic clinic. Audiotapes were used for objective assessment of question asking. Those in the intervention groups showed an increase in self-efficacy of question asking after the consultation, and less anxious patients asked more questions. No significant differences were found between intervention, attention-control, and pure control groups in the number of questions asked, however. All groups asked more questions than in previous studies, suggesting a possible ceiling effect. This example shows forcibly the need for stronger research before implementing apparently simple, feasible, but possibly ineffective, interventions in practice.

\section{Taxonomy of Process and Outcome}

The taxonomy clarifies the wide range of measures of process and outcome used. Measures may be selfreport or objective, both are clinically important and both have predictive validity. ${ }^{10,56-59}$ We differentiated health outcomes into self-reports of the illness experience and objective assessment of the disease process. Practitioners have traditionally placed more emphasis on disease processes, but patients are naturally concerned also with current well-being. Showing that positive effects on illness experiences, such as wellbeing, can coincide with negative effects on disease processes, such as dyslipidemia, ${ }^{39}$ emphasize further the need to measure both. Disease processes, however, were rarely measured.
Satisfaction, while an important health-related outcome, was excluded from our analyses of health outcomes because measures frequently overlap with the patients' subjective assessment of the consultation process. ${ }^{60,61}$

\section{Impact on Process and Outcomes}

The weight of evidence reviewed supports the hypothesis that the way practitioners and patients interact in the clinical encounter can be measured and altered. This finding is supported by other reviews. ${ }^{12}$ The effect on health-related outcomes is more equivocal. If weight is given to the direction of findings, principal outcomes favored the interventions in almost three quarters of the studies ${ }_{i}$ however, results reached statistical significance in less than one half of the studies. Among the 4 trials meeting our quality criteria, only 2 interventions were associated with significant improvements in the principal outcome. Only 2 of 6 studies with disease processes as the principal outcome significantly favored the intervention group, and 1 of 6 significantly favored the control group. Analysis by intervention type provides some promising directions, although study numbers become small.

\section{Analysis by Intervention Type}

Interventions could affect health outcomes whether aimed at patient, practitioner, or both. Almost one half of those interventions delivered via practitioners alone were associated with at least one worse outcome than the comparison group, whereas none was when delivered directly to patients. This finding is compatible with a greater positive effect of interventions directed to patients, and perhaps with the difficulties of consistently altering practitioner behavior. ${ }^{40}$

Interventions including components directed at activation of patients, activation of practitioners by preconsultation note or questionnaire from patient, and provision of information and attention to emotion, all showed promise. Significantly positive outcomes favoring the intervention group were found in more than one half of these studies. Patient activation was the approach most frequently evaluated, and there were some discordant findings. ${ }^{23,24,40}$ Two complex interventions involving patient activation among groups with chronic disease, evaluated in the United States, ${ }^{14,21}$ reported particularly large benefits, not achieved in pragmatic trials in the United Kingdom. ${ }^{39,40}$ This work merits replication.

Complexity was not necessary for success. Patients who simply provided practitioners with written information about their needs, emotional concerns, and functional status in advance of the consultation were significantly less anxious, or showed improvement in 
functional status afterward. Such written information may work as a substitute for the failure of doctors to elicit patients' ideas, concerns, and expectations, a failure that is well documented. ${ }^{7}$ Review findings also emphasize the centrality of appropriate provision of information to effective consulting ${ }^{1,39}$ and the need to further develop and evaluate affective elements. We found insufficient evidence to support a particular style of consultation in general practice or to resolve the question of whether interventions to increase patient participation prolong consultations. Further work is needed.

\section{Review Limitations}

The review has a number of strengths: we had clear inclusion criteria, a comprehensive search strategy for published trials, assessment of trial quality, attention to a priori classification of intervention types, and careful accounting of process and outcome measures. Presentation of direction, as well as statistical significance of findings, allows consideration of the overall pattern of results. The review also has limitations. The search strategy was restricted to 3 databases and to the end of 1999. Relevant studies may not have been indexed with our search terms or may be unpublished. A recent review with a broader search strategy, however, did not include any trials that met our inclusion criteria but were omitted from our review. ${ }^{9}$ Moreover, a related review including the year 2000 identified only 3 further trials with health-related outcomes. These trials did not challenge our findings. ${ }^{12}$ In addition, unpublished studies are more likely to have negative findings, ${ }^{62}$ which would only strengthen our conclusion that the evidence base is weak.

After initial unsuccessful attempts at correspondence, data were extracted and interpreted without reference to original authors, which may have led to some underestimation of trial quality and miscoding of intervention categories. ${ }^{63}$ Interventions were multifaceted and consequently were classified into more than one category. Conclusions about effectiveness of individual components of interventions are therefore limited, and none can be drawn concerning the relative effects by patient age, sex, disease and ethnic group. The heterogeneity of populations, interventions, and measures precluded overall meta-analysis, although the possibility of further synthesis among subgroups of interventions, for example, to encourage question asking by patients, or improve practitioners' communication skills, should be considered.

\section{Implications and Conclusions}

Successful interactions between patients and their practitioners lie at the heart of medicine, yet there are few rigorous trials of well-specified interventions to inform best practice. Trial evidence suggests that a range of approaches can achieve changes in this interaction and some show promise in improving patients' health. In terms of practice there are strong justifications unrelated to evidence-based medicine for adopting a collaborative approach to the medical encounter, such as, for example, patient preferences and moral imperatives. ${ }^{15}$ This review demonstrates the potential for the way patients and practitioners behave in consultations to have measurable effects, both positive and negative, on their future health. In terms of research, it demands collection of better evidence to inform practice. Improvements are needed across the board, from characterization of study populations to study designs. Outcome measures themselves should include both objective measures of disease process and self-report of illness experience where appropriate. Interventions should be more carefully developed and specified. Rigorous explanatory trials of such interventions are still needed before pragmatic studies of cost-effectiveness. To advance knowledge further, we need to replicate promising studies using rigorous methods. These studies should include explicit theoretical frameworks for interventions, designed to link effects on key characteristics of the interaction through to effects on health outcomes. Only in this way will the field advance beyond a series of tantalizing but disconnected and unconfirmed results.

To read or post commentaries in response to this article, see it online at http://www.annfammed.org/cgi/content/full/2/6/595.

Key words: Consultation; office visits; patient-centered care; outcome assessment (health care); randomized trial; systematic review

Submitted July 23, 2003; submitted, revised, January 8, 2004; accepted January 26, 2004.

Funding support: Financial support was provided by NHS Executive Eastern.

A version of this paper was presented before the North American Primary Care Research Group, November 2001; and before the Association of University Departments of General Practice, July 2000.

Acknowledgments: We acknowledge the assistance of Karen Toney and Wendy Roberts with literature searches. Paul Little, Jon Emery, Debra Roter, Julie Draper, and John Benson made valuable comments on earlier drafts. We particularly thank our 4 reviewers for their full and constructive advice on our first submission. ALK, SJG, and MS designed the protocol for the study. MWMV, KT and SG performed the literature searches. SJG, MWMV, SG, MS, and ALK assessed the studies against the inclusion criteria. Data were extracted by SJG, MWMV, SG, JG, MS, and ALK, and analyzed by SJG, MWMV, SG, JG, MS and ALK. ALK, SJG, and MS led interpretation, and SJG and ALK led paper writing. All authors agreed on the final version. SJG is the guarantor for the study. 


\section{References}

1. Silverman J, Kurtz S, Draper J. Skills for Communicating With Patients. Oxford: Radcliffe Medical Press; 1998.

2. Stewart MA, Roter D. Communicating with Medical Patients. Thousand Oaks, Calif: Sage Publications; 1989.

3. Working party appointed by The Royal College of Physicians. Improving communication between doctors and patients. J R Coll Phy sicians Lond. 1997:31:1-35.

4. Department of Health. The NHS Plan. A Plan for Investment. A Plan for Reform. London: Department of Health; 2000.

5. Stewart MA, McWhinney IR, Buck CW. The doctor/patient relationship and its effect upon outcome. J R Coll Gen Pract. 1979;29:77-81.

6. Elwyn G, Edwards A, Kinnersley P. Shared decision-making in primary care: the neglected second half of the consultation. Br J Gen Pract. 1999:49:477-482.

7. Campion P, Foulkes J, Neighbour R, Tate P. Patient centredness in the MRCGP video examination: analysis of a large cohort. BMJ. 2002:325:691-692

8. Stewart MA. Effective physician-patient communication and health outcomes: a review. CMAJ. 1995;152:1423-1433.

9. Di Blasi Z, Harkness E, Ernst E, Georgiou A, Kleijnen J. Influence of context effects on health outcomes: a systematic review. Lancet. 2001;357:757-762

10. Stewart M, Brown JB, Boon H, Galajda J, Meredith L, Sangster M. Evidence on patient-doctor communication. Cancer Prev Control. 1999;3:25-30.

11. Lewin SA, Skea ZC, Entwistle V, Zwarenstein M, Dick J. Interventions for providers to promote a patient-centred approach in clinical consultations. Cochrane Database Syst Rev. 2001:CD003267.

12. Harrington J, Noble LM, Newman SP. Improving patients' communication with doctors: a systematic review of intervention studies. Patient Educ Couns. 2004:52:7-16.

13. Roter DL, Hall JA, Kern DE, Barker LR, Cole KA, Roca RP. Improving physicians' interviewing skills and reducing patients' emotional distress. A randomized clinical trial. Arch Intern Med. 1995;155:1877-1884

14. Greenfield S, Kaplan SH, Ware JE Jr, Yano EM, Frank HJ. Patients participation in medical care: effects on blood sugar control and quality of life in diabetes. J Gen Intern Med. 1988;3:448-457.

15. Stewart M, Brown JB, Weston WW, McWhinney IR, McWilliam CL, Freeman TR. Patient-Centred Medicine: Transforming the Clinical Method. Thousand Oaks, Calif: Sage Publications; 1995.

16. Dickersin K, Scherer R, Lefebvre C. Identifying relevant studies for systematic reviews. BMJ. 1994;309:1286-1291.

17. Moher D, Jadad JR, Nichol G, Penman M, Tugwell P, Walsh S. Assessing the quality of randomized controlled trials: an annotated bibliography of scales and checklists. Controlled Clin Trials. 1995; 16:62-73.

18. Stewart MA, Roter D. Communicating with Medical Patients. Thousand Oaks, Calif: Sage Publications; 1989

19. Leventhal H, Safer MA, Panagis DM. The impact of communications of self-regulation of health beliefs, decisions and behaviour. Health Educ Q. 1983;10:3-29.

20. Thompson SC, Nanni C, Schwankovsky L. Patient-oriented interventions to improve communication in a medical office visit. Health Psychol. 1990;9:390-404.

21. Kaplan SH, Greenfield S, Ware JE Jr. Assessing the effects of physician-patient interactions on the outcomes of chronic disease. Med Care. 1989;27:S110-S127.

22. Greenfield S, Kaplan S, Ware JE Jr. Expanding patient involvement in care. Effects on patient outcomes. Ann Intern Med. $1985 ; 102: 520-528$
23. Butow PN, Dunn SM, Tattersall MH, Jones QJ. Patient participation in the cancer consultation: evaluation of a question prompt sheet. Ann Oncol. 1994;5:199-204.

24. Street RL Jr, Voigt B, Geyer C Jr, Manning T, Swanson GP. Increasing patient involvement in choosing treatment for early breast cancer. Cancer. 1995; 76:2275-2285.

25. McCann S, Weinman J. Empowering the patient in the consultation: a pilot study. Pat Educ Couns. 1996;27:227-234.

26. Davison BJ, Degner LF. Empowerment of men newly diagnosed with prostate cancer. Cancer Nurs. 1997;20:187-196.

27. Kravitz RL, Callahan EJ, Azari R, Antonius D, Lewis CE. Assessing patients' expectations in ambulatory medical practice. Does the measurement approach make a difference? J Gen Intern Med. $1997 ; 12: 67-72$

28. Flessig A, Glasser B, Lloyd M. Encouraging out-patients to make the most of their first hospital appointment: to what extent can a written prompt help patients get the information they want? Pat Educ Couns. 1999:38:69-79.

29. Thomas KB. The consultation and the therapeutic illusion. BMJ. 1978; 1:1327-1328

30. Schulman BA, Swain MA. Active patient orientation. Patient Couns Health Educ. 1980;2:32-37.

31. Evans BJ, Kiellerup FD, Stanley RO, Burrows GD, Sweet B. A communication skills programme for increasing patients' satisfaction with general practice consultations. Br J Med Psychol. 1987;60:373-378.

32. Thomas KB. General practice consultations: is there any point in being positive? BMJ. 1987;294:1200-1202.

33. Olsson B, Olsson B, Tibblin G. Effect of patients' expectations on recovery from acute tonsillitis. Fam Pract. 1989;6:188-192.

34. Savage R, Armstrong D. Effect of a general practitioner's consulting style on patients' satisfaction: a controlled study. BMJ. 1990;301:968-970.

35. Evans BJ, Stanley RO, Burrows GD. Communication skills training and patients' satisfaction. Health Commun. 1992;4:155-170.

36. Smith RC, Lyles JS, Mettler JA, et al. A strategy for improving patient satisfaction by the intensive training of residents in psychosocial medicine: a controlled, randomized study. Acad Med. 1995;70:729-732.

37. Meland E, Laerum E, Ulvik RJ. Effectiveness of two preventive interventions for coronary heart disease in primary care. Scand J Prim Health Care. 1997:15:57-64.

38. Meland E, Laerum E, Maeland JG. Life style intervention in general practice: effects on psychological well-being and patient satisfaction. Qual Life Res. 1996;5:348-354.

39. Kinmonth AL, Woodcock A, Griffin S, Spiegal N, Campbell MJ. Randomised controlled trial of patient centred care of diabetes in general practice: impact on current wellbeing and future disease risk. The Diabetes Care From Diagnosis Research Team. BMJ. 1998; 317:1202-1208.

40. Pill R, Stott NCH, Rollnick SR, Rees M. A randomized controlled trial of an intervention designed to improve the care given in general practice to Type II diabetic patients: patient outcomes and professional ability to change behaviour. Fam Pract. 1998;15:229-235.

41. Smith RC, Lyles JS, Mettler J, et al. The effectiveness of intensive training for residents in interviewing. Ann Intern Med. 1998;128:118-126.

42. Peters T, Somerset M, Baxter K, Wilkinson C. Anxiety among women with mild dyskaryosis: a randomized trial of an educational intervention. Br J Gen Pract. 1999;49:348-352

43. Thom DH, Bloch DA, Segal E. An intervention to increase patients trust in their physicians. Acad Med. 1999;74:195-198.

44. Brown Betz J, Boles M, Mullooly J, Levinson W. Effect of clinician communication skills training on patient satisfaction. Ann Intern Med. $1999 ; 131: 822-829$ 
45. Lewis CC, Pantell RH, Sharp L. Increasing patient knowledge, satisfaction, and involvement: randomized trial of a communication intervention. Pediatrics. 1991;88:351-358.

46. Katon W, Von Korff M, Lin E, et al. Collaborative management to achieve treatment guidelines. Impact on depression in primary care. JAMA. 1995;273:1026-1031.

47. Rubenstein LV, McCoy JM, Cope DW, et al. Improving patient quality of life with feedback to physicians about functional status. J Gen Intern Med. 1995;10:607-614.

48. Joos SK, Hickam DH, Gordon GH, Baker LH. Effects of a physician communication intervention on patient care outcomes. J Gen Intern Med. 1996;11:147-155.

49. Hornberger J, Thom D, MaCurdy T. Effects of a self-administered previsit questionnaire to enhance awareness of patients' concerns in primary care. J Gen Intern Med. 1997;12:597-606.

50. Wagner AK, Ehrenberg BL, Tran TA, Bungay KM, Cynn DJ, Rog ers WH. Patient-based health status measurement in clinical practice: a study of its impact on epilepsy patients' care. Qual Life Res. 1997;6:329-341

51. Maly RC, Bourque L, Engelhardt R. A randomized controlled trial of facilitating information giving to patients with chronic medical conditions. J Fam Pract. 2001;48:356-363.

52. Reuben DB, Frank JC, Hirsch SH, McGuigan KA, Maly RC. A randomized clinical trial of outpatient comprehensive geriatric assessment coupled with an intervention to increase adherence to recommendations. J Am Geriatr Soc. 1999;47:269-276.

53. Campbell M, Fitzpatrick R, Haines $A$, et al. Framework for design and evaluation of complex interventions to improve health. BMJ. 2000:321:694-696.
54. Kidd, J, Marteau TM, Robinson S, Ukoumunne OC, Tydeman C. Promoting patient participation in consultations: a randomised controlled trial to evaluate the effectiveness of three patient-focused interventions. Pat Educ Couns. 2004;52:107-112.

55. Roter DL. Patient participation in the patient-provider interaction: the effects of patient question asking on the quality of interaction, satisfaction and compliance. Health Educ Monogr. 1977; 5:281-315.

56. Little P, Everitt H, Williamson I, et al. Observational study of effect of patient centredness and positive approach on outcomes of general practice consultations. BMJ. 2001;323:908-911.

57. Stewart M, Brown JB, Donner A, et al. The impact of patient-centered care on outcomes. J Fam Pract. 2000;49:796-804.

58. Davis WK, Hess GE, Hiss RG. Psychosocial correlates of survival in diabetes. Diab Care. 1988;11:538-545.

59. Stratton I, Adler AG, Neil HA, et al. Association of glycaemia with macrovascular and microvascular complications of type 2 diabetes (UKPDS 35): prospective observational study. BMJ. 2000;321:405-412.

60. Rosenthal GE, Shannon SE. The use of patient perceptions in the evaluation of health-care delivery systems. Med Care. 1997;35: NS58-NS68.

61. Starfield B. Patient-Practitoner Interactions. Primary Care. Oxford: Oxford University Press; 1998:176.

62. Egger M, Davey Smith G. Meta-analysis. Bias in location and selection of studies. BMJ. 1998;316:61-66.

63. Soares HP, Daniels S, Kumar A, et al. Bad reporting does not mean bad methods for randomised trials: observational study of randomised controlled trials performed by the Radiation Therapy Oncology Group. BMJ. 2004;328:22-24. 